\title{
Synthesis of Highly Substituted Indolines and Indoles via Intramolecular [4 + 2] Cycloaddition of Ynamides and Conjugated Enynes
}

\author{
Joshua R. Dunetz and Rick L. Danheiser \\ Department of Chemistry, Massachusetts Institute of Technology, Cambridge, Massachusetts \\ 02139
}

\begin{abstract}
The invention of new synthetic routes to indoles and indolines continues to command wide interest due to the numerous natural products and biologically significant compounds whose structures incorporate these heterocyclic systems. ${ }^{1}$ A number of useful strategies are now available for the synthesis of indoles substituted on the five-membered ring, the majority of which involve the elaboration of the heterocyclic system from an aniline, $o$-halo aniline, or other 2-substituted aniline derivative. In contrast, few existing methods provide efficient and regiocontrolled access to indoles that are highly substituted on the benzenoid ring.
\end{abstract}

Intramolecular cycloaddition strategies provide a powerful vehicle for the direct assembly of the bicyclic indole ring system from acyclic precursors. ${ }^{2}$ Herein we report a new intramolecular $[4+2]$ cycloaddition strategy that is particularly useful for the construction of indolines and indoles bearing multiple substituents on the six-membered ring. This approach is highly modular and is especially well-suited for the preparation of libraries of substituted indole derivatives.

The new indole synthesis is based on the extension of our earlier work on enyne cycloadditions $^{3-5}$ to include reactions of ynamide ${ }^{6}$ and enynamide derivatives as $2 \pi$ and $4 \pi$ cycloaddition components. In a typical reaction, heating enynes of type 1 promotes a [4+2] cycloaddition which generates a highly strained isoaromatic cyclic allene that rearranges via proton or hydrogen atom transfer pathways to afford the desired indoline (Scheme 1). ${ }^{7}$ An especially attractive feature of this strategy is the ease with which the requisite enyne cycloaddition substrates can be assembled via transition-metal-mediated coupling reactions (vide infra).

Initial feasibility studies were conducted using enynes such as $\mathbf{5}$, whose preparation illustrates our convenient modular approach to the assembly of cycloaddition substrates. As outlined in eq 1, 3-butynylamine serves as a synthetic linchpin in this divergent strategy. Sonogashira coupling of $\mathbf{4}$ with an alkenyl halide or sulfonate generates the requisite enyne moieties with a variety of substitution patterns, and our room-temperature copper-promoted $\mathrm{N}$ alkynylation $^{8,9}$ reaction then provides access to the desired substituted ynamides. ${ }^{10}$

*danheisr@mit.edu .

Supporting Information Available: Experimental procedures and characterization data for all indolines and indoles. Full details on the synthesis of all cycloaddition substrates. This material is available free of charge via the Internet at http://pubs.acs.org. 


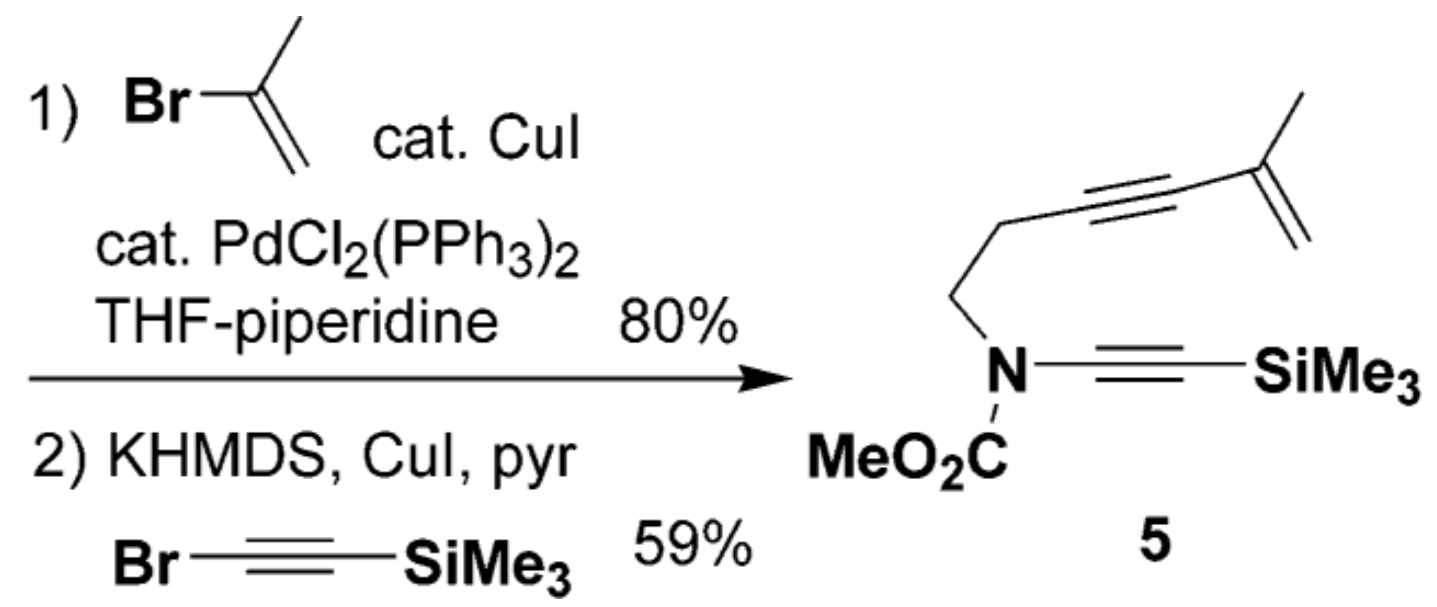

Tables 1 and 2 delineate the scope of the [4+2] cycloaddition. Thermal cycloadditions take place in toluene at temperatures ranging from 110 to $210{ }^{\circ} \mathrm{C}$, depending on the degree of activation of the $2 \pi$ ("enynophile") component. As noted previously, ${ }^{3}$ reactions conducted in the presence of BHT proceed in somewhat improved yield (Table 2, entries 1 and 2), although this additive has little effect on the rate of reaction. BHT is believed to suppress polymerization of the enyne substrates, but this phenol may also serve as a proton and/or hydrogen atom donor facilitating the isomerization of the intermediate cyclic allene $\mathbf{2}$ to the indoline product $\mathbf{3}$. Trifluoroethanol, which can function as a non-nucleophilic proton donor, also proved to be an excellent solvent for the cycloaddition in the absence of BHT. Finally, a noteworthy finding is that Lewis acids have the capacity to serve as powerful promoters of the cycloaddition in cases involving enynophiles with carbonyl activating groups. For example, exposure of alkynyl ester 25 to $\mathrm{Me}_{2} \mathrm{AlCl}$ in $\mathrm{CH}_{2} \mathrm{Cl}_{2}$ leads to efficient cycloaddition at $0-25^{\circ} \mathrm{C}$ to furnish the desired cycloadduct $\mathbf{3 0}$ in $\mathbf{7 8 \%}$ yield. Significantly, no reaction of alkynylsilane $\mathbf{2 7}$ was observed to take place under identical conditions.

The facility of cycloadditions involving diynamides 11-14 as enynophiles is particularly notable. These cycloadditions proceed in refluxing toluene and give rise to indolines bearing carbon substituents at the $\mathrm{C}-7$ position. These reactions are also synthetically significant, since the cycloadducts can be easily elaborated (e.g., by hydrogenation) to furnish indolines that are not available in good yield directly via ynamide cycloadditions. ${ }^{11}$ To our knowledge, these reactions represent the first synthetic applications of diynamides, an interesting class of synthetic building blocks with considerable potential in organic synthesis.

One significant limitation of the cycloaddition of conjugated enynes with ynamides is that the indoline products necessarily bear a hydrogen at the C-4 position. Access to indolines substituted at this site can be gained, however, via the reactions of conjugated enynamides. As summarized in Table 2, the cycloaddition of these electron-rich enynes is unusually facile and provides an efficient route to C-4 substituted indolines that is complementary to the reactions outlined in Table 1.

Finally, oxidation of the indoline cycloaddition products was conveniently achieved employing $o$-chloranil ${ }^{12}$ in benzene at room temperature to afford indoles such as $\mathbf{3 5}$ and $\mathbf{3 6}$ in good yield. In the case of indoline 30, however, partial dehydrogenation of the cyclohexyl ring was observed under these conditions, and the desired indole (37) was obtained in only modest yield. This problem was easily circumvented by carrying out the oxidation on the deprotected indoline 
38 (eq 2). In this case, hydride abstraction from the $\mathrm{C}-2$ position is a more facile process, and indole 39 was obtained in excellent yield without over-oxidation.

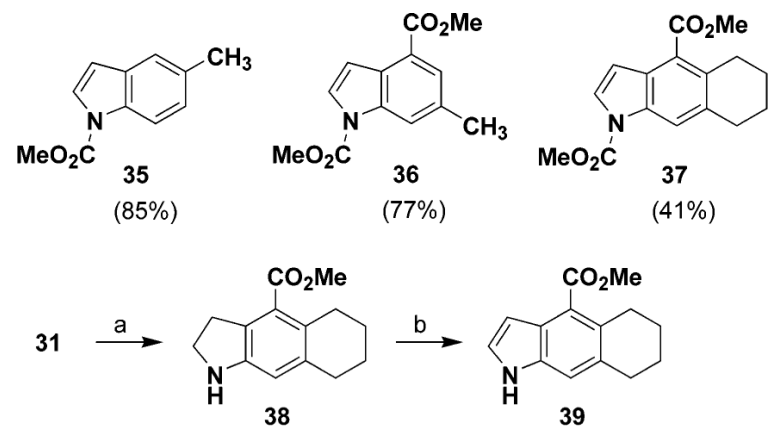

(a) TFA- $\mathrm{CH}_{2} \mathrm{Cl}_{2}, \mathrm{rt}, 97 \%$; (b) 1 equiv $o$-chloranil, benzene, rt, $88 \%$

\section{Supplementary Material}

Refer to Web version on PubMed Central for supplementary material.

\section{Acknowledgments}

We thank the National Institutes of Health (GM 28273) and Merck Research Laboratories for generous financial support.

\section{References}

(1). For reviews of indole and indoline chemistry, see: (a) Joule, JA. Science of Synthesis. Thomas, EJ., editor. Vol. Vol. 10. Thieme; Stuttgart: 2000. p. 361-652.. (b) Sundberg, RJ. Indoles. Academic Press; London: 1996. .

(2). For examples of the synthesis of indoles and indolines via intramolecular [4 + 2] cycloadditions, see: (a) Boger DL, Coleman RS. J. Org. Chem 1984;49:2240.. (b) Hayakawa K, Yasukouchi T, Kanematsu K. Tetrahedron Lett 1986;27:1837.. (c) Padwa A, Brodney MA, Liu B, Satake K, Wu T. J. Org. Chem 1999;64:3595. [PubMed: 11674487] . (d) Witulski B, Lumtscher J, Bergsträsser U. Synlett 2003;708.

(3). (a) Danheiser RL, Gould AE, Fernández de la Pradilla R, Helgason AL. J. Org. Chem 1994;59:5514. (b) Wills MSB, Danheiser RL. J. Am. Chem. Soc 1998;120:9378. and references therein.

(4). For related cycloadditions of conjugated arenynes (the "Michael-Bucher reaction"), see Rodríguez D, Martínez-Esperón MF, Navarro-Vázquez A, Castedo L, Domínguez D, Saá C. J. Org. Chem 2004;69:3842. and references therein. [PubMed: 15153017].

(5). For reviews of transition-metal-catalyzed enyne cycloadditions, see: (a) Rubin M, Sromek AW, Gevorgyan V. Synlett 2003:2265.. (b) Saito S, Yamamoto Y. Chem. Rev 2000;100:2901. [PubMed: 11749309].

(6). For reviews of ynamide chemistry, see: (a) Mulder JA, Kurtz KCM, Hsung RP. Synlett 2003:1379.. (b) Zificsak CA, Mulder JA, Hsung RP, Rameshkumar C, Wei L-L. Tetrahedron 2001;57:7575..

(7). For mechanistic and theoretical studies on enyne and arenyne cycloadditions, see: (a) Burrell RC, Daoust KJ, Bradley AZ, DiRico KJ, Johnson RP. J. Am. Chem. Soc 1996;118:4218.. (b) Ananikov VP. J. Phys. Org. Chem 2001;14:109.. (c) Rodríguez D, Navarro-Vázquez A, Castedo L, Domínguez D, Saá C. J. Org. Chem 2003;68:1938. [PubMed: 12608814] .

(8). Dunetz JR, Danheiser RL. Org. Lett 2003;5:4011. [PubMed: 14535766]

(9). Alternative $\mathrm{N}$-alkynylation methods catalytic in copper require elevated temperatures and were not suitable for the preparation of these cycloaddition substrates. See: (a) Zheng Y, Hsung RP, Tracey MR, Kurtz KCM, Vera EL. Org. Lett 2004;6:1151. [PubMed: 15040745] . (b) Frederick MO, 
Mulder JA, Tracey MR, Hsung RP, Huang J, Kurtz KCM, Shen L, Douglas CJ. J. Am. Chem. Soc 2003;125:2368. [PubMed: 12603105] .

(10). The $N$-sulfonyl ynamides 6-9 were prepared by alkynylation with alkynyl-(phenyl)iodonium salts. See: Witulski B, Stengel T. Angew. Chem., Int. Ed 1998;37:489..

(11). Cycloadditions involving ynamides with alkyl substituents (i.e., $\mathbf{1}, \mathrm{R}^{3}=\mathrm{Hex}, \mathrm{CH}_{2} \mathrm{OMe}$ ) were found to proceed in poor yield.

(12). See ref 1 and (a) Zhang D, Liebeskind LS. J. Org. Chem 1996;61:2594. [PubMed: 11667083] . (b) Bailey WF, Jiang X-L. J. Org. Chem 1996;61:2596. [PubMed: 11667084] . 

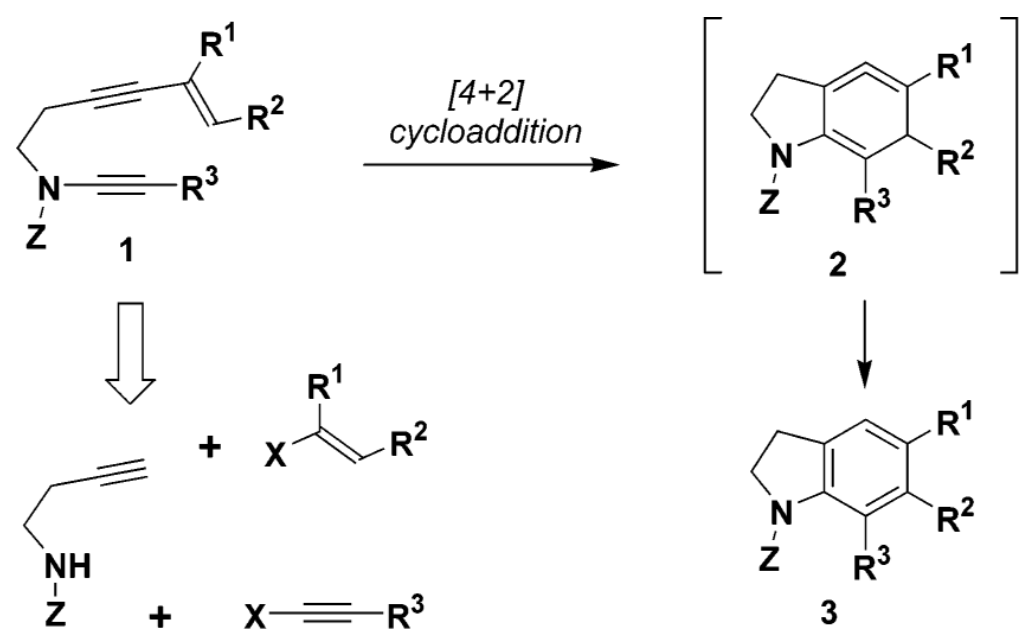

Scheme 1. 


\section{Table 1}

[4 + 2] Cycloadditions of Conjugated Enynes with Ynamides

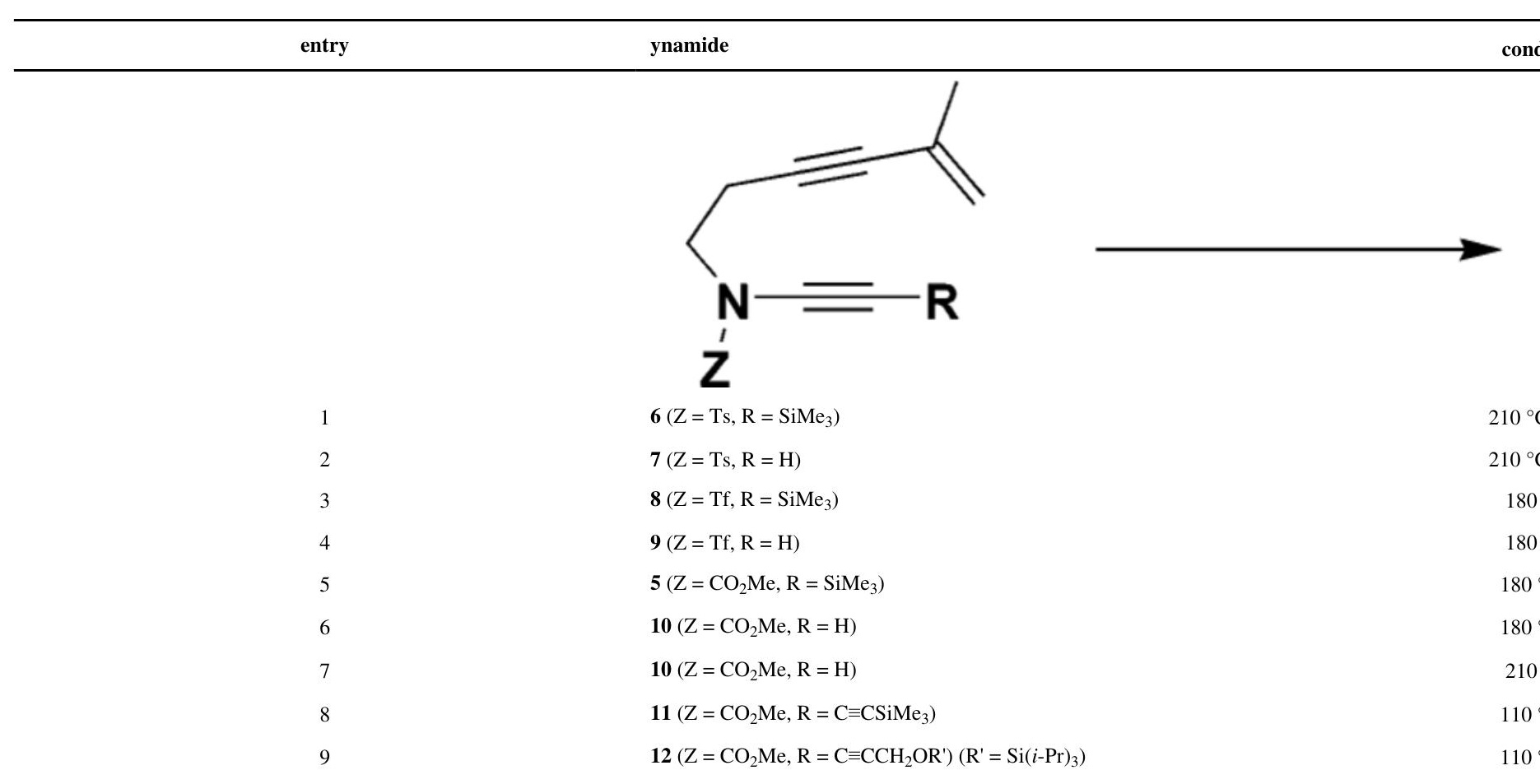




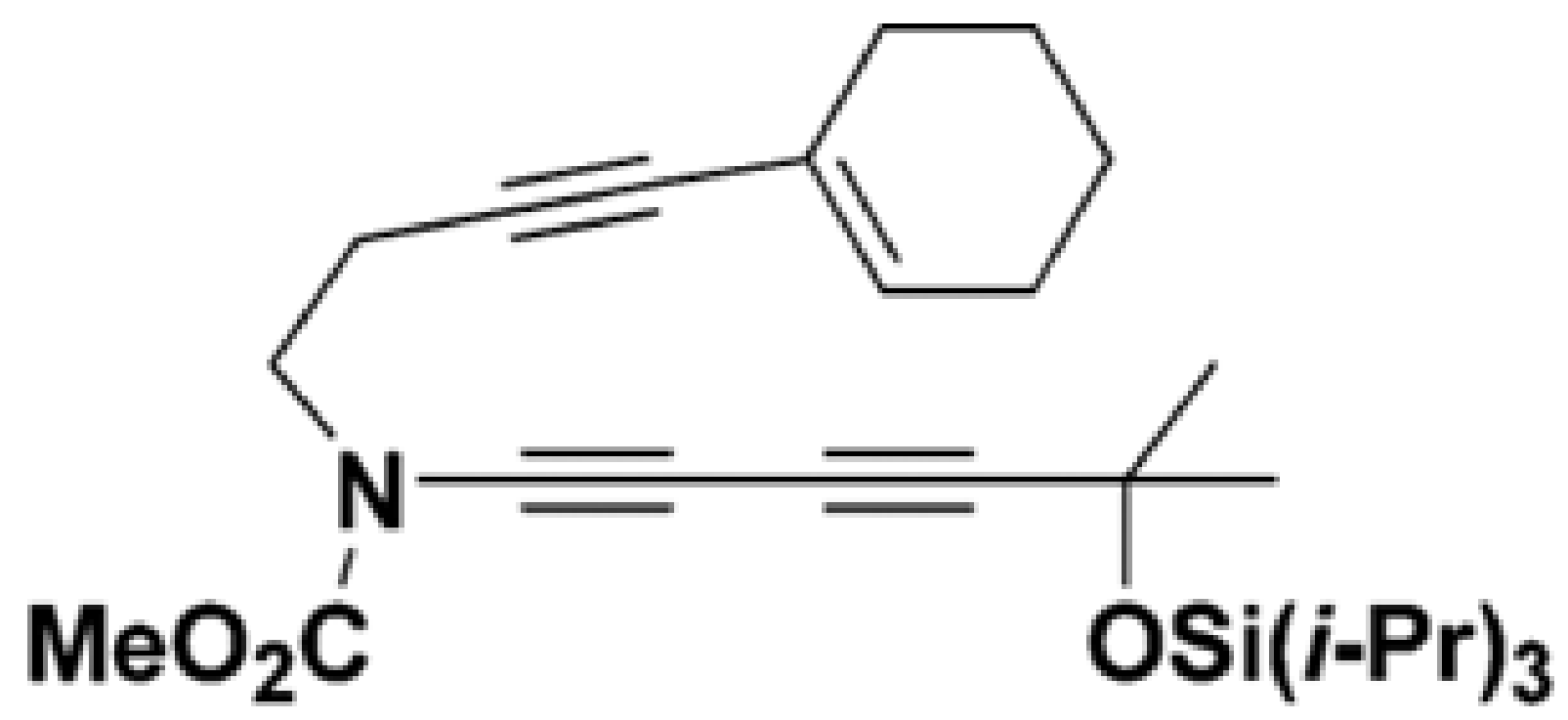

10

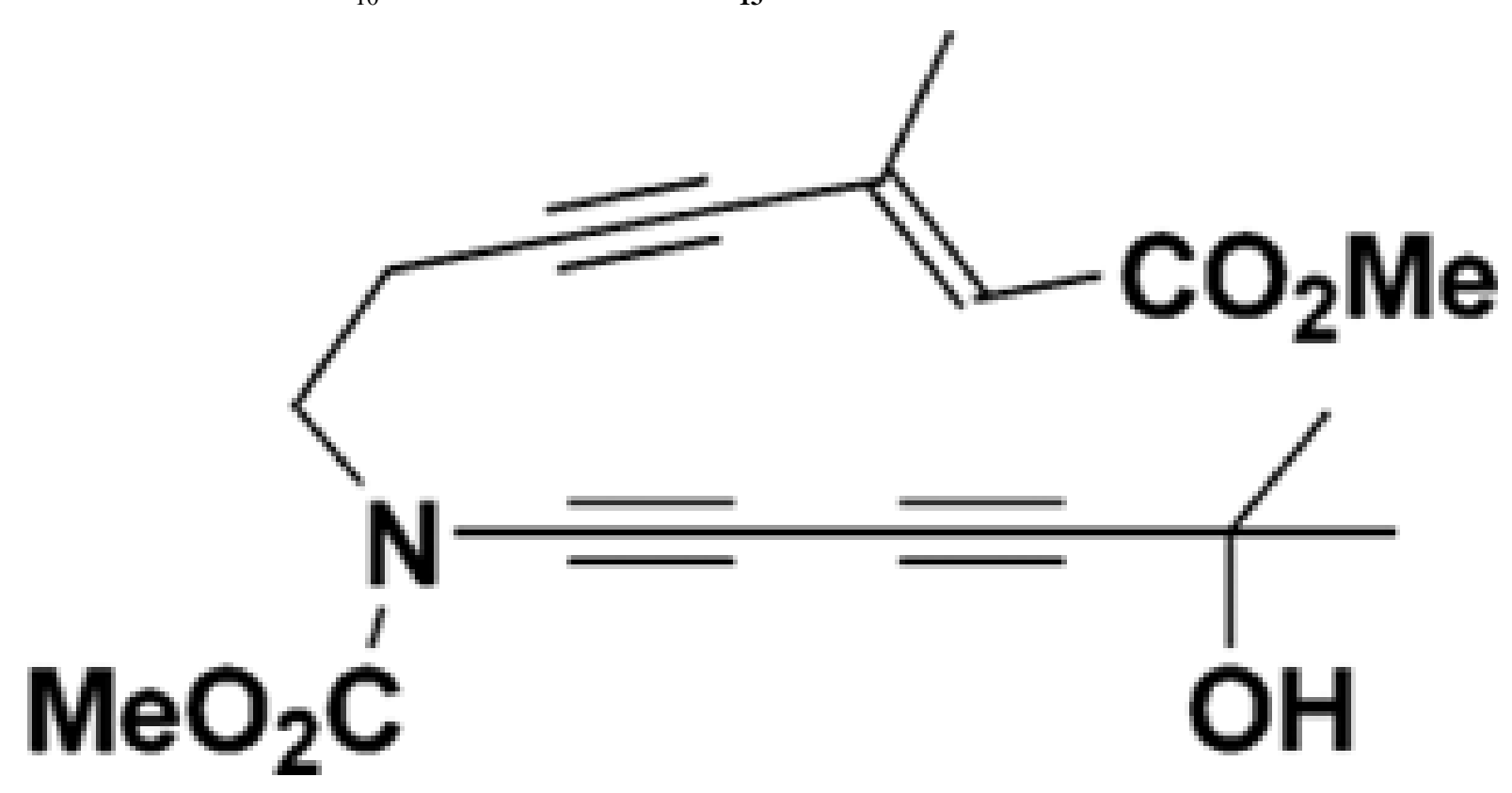

$J$ Am Chem Soc. Author manuscript; available in PMC 2010 June 28. 


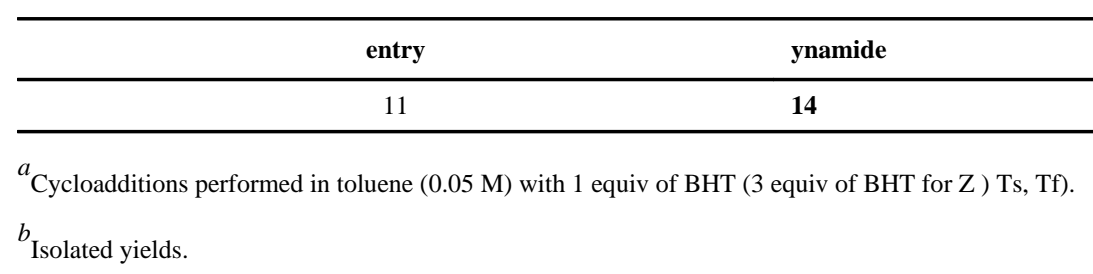


Table 2

[4 + 2] Cycloadditions of Conjugated Enynamides with Alkynes

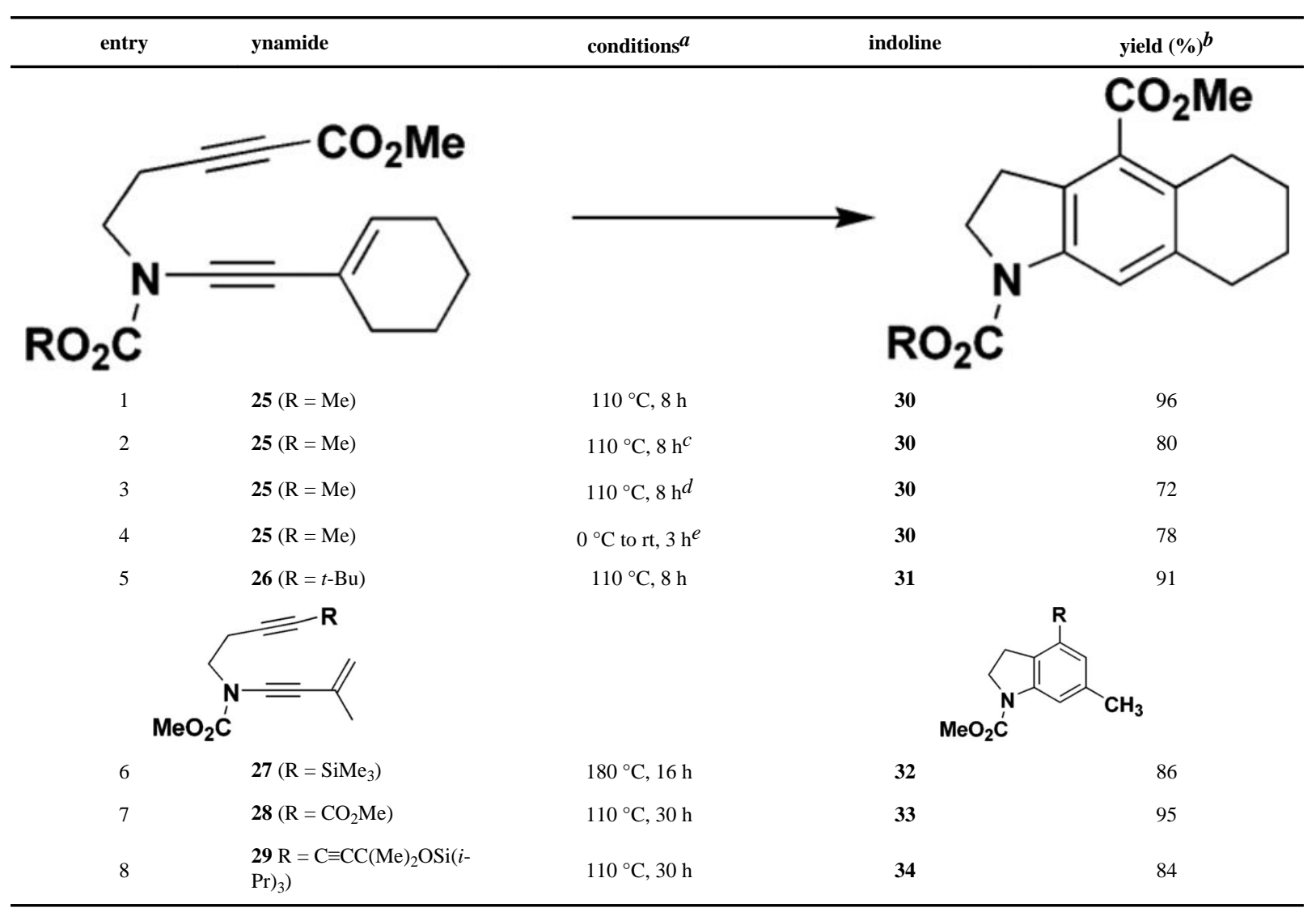

${ }^{a}$ Cycloadditions performed in toluene $(0.05 \mathrm{M})$ with 1 equiv of BHT unless otherwise indicated.

$b_{\text {Isolated yields. }}$

${ }^{c}$ Reaction in the absence of BHT.

$d_{\text {Reaction in TFE (0.05 M) without BHT. }}$.

${ }^{e}$ Reaction in the presence of 2.5 equiv of $\mathrm{Me}_{2} \mathrm{AlCl}$ in $\mathrm{CH}_{2} \mathrm{Cl}_{2}(0.05 \mathrm{M})$ without BHT. 